Article

\title{
Patterns of Ecological Adaptation of Aedes aegypti and Aedes albopictus and Stegomyia Indices Highlight the Potential Risk of Arbovirus Transmission in Yaoundé, the Capital City of Cameroon
}

\author{
Armel N. Tedjou ${ }^{1,2, *, \dagger}$, Basile Kamgang ${ }^{1, *,+} \oplus$, Aurélie P. Yougang ${ }^{1,2}$, \\ Theodel A. Wilson-Bahun ${ }^{1,3}$, Flobert Njiokou ${ }^{2}$ and Charles S. Wondji 1,4 (D) \\ 1 Department of Medical Entomology, Centre for Research in Infectious Diseases, 15391 Yaoundé, Cameroon; \\ aurelie.yougang@crid-cam.net (A.P.Y.); wilsontheodel9@gmail.com (T.A.W.-B.); \\ charles.wondji@lstmed.ac.uk (C.S.W.) \\ 2 Department of Animal Biology and Physiology, Faculty of Sciences, University of Yaoundé I, 812 Yaoundé, \\ Cameroon; njiokouf@yahoo.com \\ 3 Department of Animal Biology and Physiology, Faculty of Sciences and Technology, \\ Marien Ngouabi University, Brazzaville, Congo \\ 4 Vector Biology Department, Liverpool School of Tropical Medicine, Pembroke Place, Liverpool L3 5QA, UK \\ * Correspondence: armel.tedjou@crid-cam.net (A.N.T.); basile.kamgang@crid-cam.net (B.K.) \\ + These authors contributed equally to this work.
}

Received: 2 June 2020; Accepted: 17 June 2020; Published: 20 June 2020

\begin{abstract}
The dynamic of arbovirus vectors such as Aedes aegypti and Ae. albopictus remains poorly understood in large cities in central Africa. Here, we compared the larval ecology, geographical distribution and degree of infestation of Ae. aegypti and Ae. albopictus in Yaoundé, the capital city of Cameroon, and estimated their Stegomyia indices revealing a significant potential risk of arbovirus transmission. An entomological survey was conducted in April-May 2018 in a cluster of houses randomly selected. Each selected house was inspected, the number of inhabitants was recorded, and potential and positive containers for Aedes were characterized. Stegomyia and pupae-based indices were estimated. Overall, 447 houses and 954 containers were inspected comprising 10,801 immature stages of Aedes with $84.95 \%$ of Ae. albopictus and $15.05 \%$ of Ae. aegypti. Both species bred mainly in discarded tanks and used tyres, associated with turbid water and the presence of plant debris inside containers. Aedes albopictus was the most prevalent species in almost all neighbourhoods. The house index, Breteau index, and container index were higher for Ae. albopictus (38.26\%, 71.81\%, and 29.61\%) compared to those of Ae. aegypti (25.73\%, 40.93\%, and $16.88 \%)$. These indices are high compared to the thresholds established by Pan American Health Organization and World Health Organization, which suggests a high potential risk of arbovirus transmission.
\end{abstract}

Keywords: Aedes albopictus; Aedes aegypti; Stegomyia indices; arbovirus; Cameroon

\section{Introduction}

Aedes-borne diseases such as dengue, yellow fever, Zika and chikungunya have emerged in several tropical and subtropical regions worldwide [1]. The viruses that cause these diseases are transmitted to humans by a bite from infected mosquitoes belonging to the Aedes genus, notably Aedes aegypti (Linnaeus 1762) and Aedes albopictus (Skuse 1894) [2].

Aedes aegypti, native to the African continent [3,4], has a cosmo-tropical distribution while Ae. albopictus, originating from the south-east Asian forest, has invaded all five continents over the 
last four decades [5-8]. The rapid spread of Ae. albopictus across the world may be due to the international commercialization of used tyres [9] and its strong ecological plasticity which allows it to adapt to different environments [10]. Aedes albopictus was reported for the first time in central Africa in Cameroon in the early 2000s [11] and has progressively colonized almost all countries in the region [12]. Despite the fact that both species have a different origin, these mosquitoes have a similar ecology, ovipositing in man-made water containers $[13,14]$ and feeding generally on human blood $[15,16]$. In fact, the coexistence of both species has been well documented [14,17]. In the sympatric areas notably in Africa, both species have often colonized the same breeding sites with the difference that Ae. albopictus breeds preferentially in containers surrounded by the presence of vegetation while Ae. aegypti prefers man-made containers located in neighbourhoods with high building density [18-20]. It has been demonstrated that the coexistence of both species is due to the segregation of the habitat according to macro-environmental factors such as building density and vegetation index $[14,18,19,21]$.

The competitive displacement of Ae. aegypti after the invasion of Ae. albopictus has been documented in Brazil [14,22,23], Florida [14,24], and Australia [25,26] and was suspected in several countries and territories such as La Reunion [27,28], Mayotte [29], the Republic of the Congo [30] and the Central African Republic [19]. In contrast, in Asia, Ae. aegypti has an overall competitive advantage over Ae. albopictus, especially in urban areas [31,32]. Previous studies in Cameroon demonstrated that Ae. aegypti is found across the country whereas Ae. albopictus has a distribution limited in the southern part of the country and tends to replace the resident species Ae. aegypti [33,34]. Detailed studies conducted in Yaoundé (Cameroon) in 2007 globally highlighted the predominance of Ae. albopictus but showed no significant difference between the geographical distribution of the two species according to the environment [18]. As both Aedes species share the same ecological niche and probably exploit the same resources in Yaoundé, it was suggested that the competition between them is ongoing but no species had yet taken over, and a decade later there is a need to assess the state of this competition. In addition, the current Stegomyia indices of both species remain unclear or need to be updated to adjust vector control strategies in order to prevent arbovirus outbreaks.

Aedes-borne diseases such as dengue especially were once considered scarce in Cameroon. However, during the past decade, cases of dengue have increasingly been reported [35-39] suggesting an active circulation of this virus in Cameroon. In addition, vector competence analysis showed that both Ae. albopictus and Ae. aegypti from central Africa are able to transmit the yellow fever virus [40], dengue virus [41], and Zika virus [42]. Until now, apart from yellow fever for which there is a vaccine, there has been no specific treatment or effective vaccine against these viruses. Thus, vector control and surveillance remain the cornerstone of preventing Aedes-borne diseases. In this study we present comparative data on the current geographical distribution, larval ecology, and level of infestation of Ae. aegypti and Ae. albopictus in Yaoundé based on the Stegomyia indices.

\section{Results}

\subsection{Pre-Imaginal Infestation}

Overall, 447 houses in 30 neighbourhoods were investigated with 4471 inhabitants and an average of ten persons per house. A total of 955 potential containers were prospected from which $360(37.7 \%)$ were found to be positive for the aquatic stages of Ae. aegypti and/or Ae. albopictus. Several other mosquito species were identified in association with Ae. albopictus and/or Ae. aegypti during the survey, including Ae. simpsoni (Theobald 1905), Anopheles gambiae s.l. (Giles 1902), Culex tigripes (De Grandpré and De Charmoy 1900), Culex pipiens quinquefasciatus (Say 1823), Culex antennatus (Beker 1903), Culex sp. (Linnaeus 1758), Eretmapodites brevipalpis (Ingram and De Meillon 1927), and Toxhorynchites brevipalpis (Ribeiro 1991). Overall, the proportion of containers infested by Ae. albopictus was significantly higher than that infested by Ae. aegypti $\left(\chi^{2}=37.78, d f=1, p<10^{-9}\right)$. Similarly, the proportion of containers infested by Ae. albopictus (28.1\%) was significantly higher than that infested by Ae. aegypti $(15 \%)$ in downtown as well as in suburban (Ae. albopictus: $44.7 \%$; Ae. aegypti: $18.6 \%)$ areas $(p<0.01)$, whereas 
no significant difference was observed in rural areas $(p>0.05)$ (Table S1). The proportion of containers infested by Ae. albopictus only (49.2\%), Ae. aegypti only (10.8\%) and by both species (40\%) differed significantly $\left(\chi^{2}=34.1, d f=2, p<10^{-8}\right.$ ) (Table 1$)$. Of the 30 neighbourhoods, only one was negative for Aedes species, the Briqueterie neighbourhood where no immature stage of Ae. albopictus and/or Ae. aegypti was reported in houses surveyed (Table 1, Table S1).

\subsection{Larval/Pupal Indices and Risk of Dengue and Yellow Fever Transmission}

The house (HI), Breteau (BI), and container indices (CI) were assessed to establish the potential risk of dengue and yellow fever transmission in Yaoundé. The overall HI was 40.5\% (95\%CI, 38.2-42.8) in Yaoundé and varied from 23 in Yaoundé II to $45 \%$ in Yaoundé III with no significant difference $\left(\chi^{2}=10.2, d f=6, p>0.05\right)$ (Table S2). Analysis conducted between species revealed that the overall HI for Ae. albopictus (38.3\%; 95\%CI, 36.0-40.6\%) was significantly higher than the HI for Ae. aegypti $(25.7 \% ; 95 \% \mathrm{CI}, 23.7-27.8 \%)\left(\chi^{2}=24.7, d f=6, p<0.001\right)$. Analysis according to borough showed that the HIs for Ae. albopictus were significantly higher than those for Ae. aegypti $(p<0.05)$ (Table S2, Figure 1a). Globally, the BI for Aedes spp. was 80.5\% (95\%CI, 74.4-86.6\%) in Yaoundé and ranged from $50 \%$ to $108 \%$ with no significant difference (ANOVA, $\mathrm{F}=1.44, d f=6, p>0.05$ ). Analysis according to the Aedes species showed that the BI for Ae. albopictus 71.8\% (95\%CI, 66.2-77.4\%) was significantly higher compared to that of Ae. aegypti, 40.9\% (95\%CI, 37-44.8\%) (ANOVA, F = 320.1, $d f=1, p<0.001$ ). However, the BI for Ae. albopictus populations varied from $45 \%$ in Yaoundé II to $92 \%$ in Yaoundé VII with no significant difference (ANOVA, $\mathrm{F}=0.93, d f=6, p>0.05$ ). In contrast, BIs in Ae. aegypti populations varied significantly from $26 \%$ in Yaoundé $\mathrm{V}$ to $74 \%$ in Yaoundé VII (ANOVA, $\mathrm{F}=3.20$, $d f=6, p<0.01$ ) (Table S2, Figure 1b). Similar analysis was performed for the container index and revealed that globally the CI was 33.2\% (95\%CI, 31.8-34.6\%) with no significant difference according to borough $\left(\chi^{2}=13.3, d f=6, p>0.05\right)$. A similar trend to the $\mathrm{HI}$ and BI was observed for the $\mathrm{CI}$ when analysing according to Aedes species; the CI calculated for Ae. albopictus (29.6\%; 95\%CI, 28.2-31\%) was significantly higher than that of Ae. aegypti (16.9\%; 95\%CI, 15.7-18\%) in Yaoundé $\left(\chi^{2}=38.4, d f=6\right.$, $p<0.001$ ) (Table S2, Figure 1c). Based on the estimated indices for Ae. aegypti in reference to threshold levels for dengue and yellow fever transmissions established by Pan American Health Organization (PAHO) [43] and World Health Organization (WHO) [44], the city of Yaoundé could be classified as a high-potential risk area for arbovirus transmissions, notably dengue and yellow fever (Figure 1).
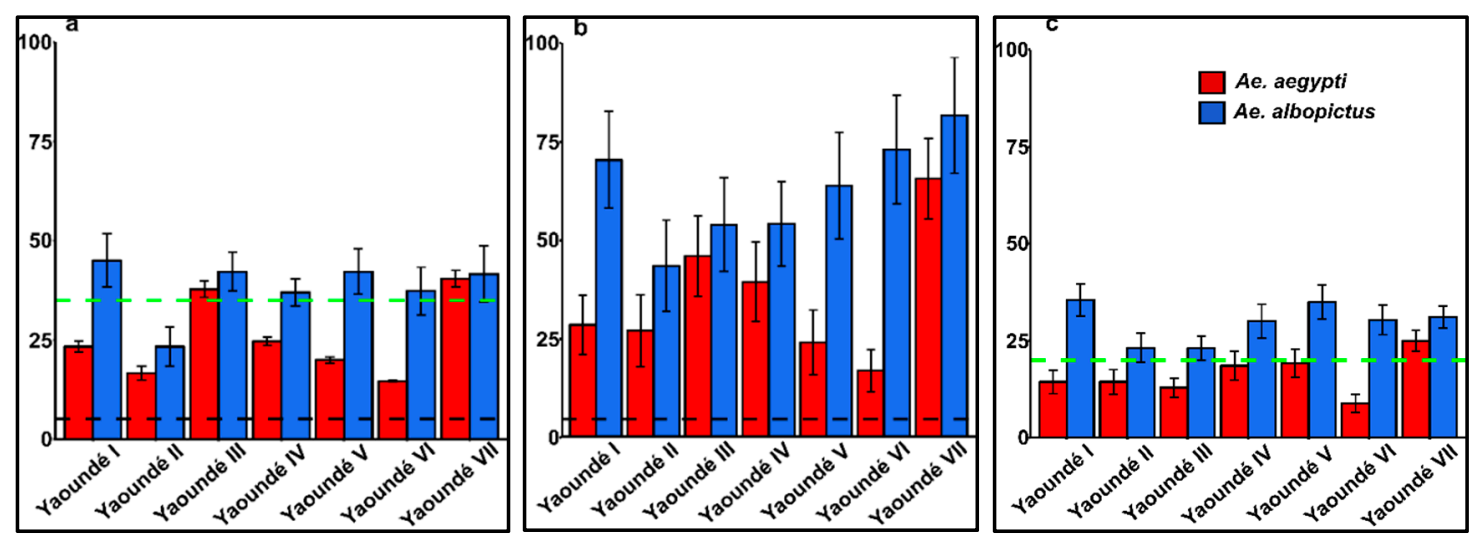

Figure 1. Stegomyia indices of Ae. albopictus and Ae. aegypti in Yaoundé; (a) House index (HI); (b) Breteau index (BI); and (c) container index (CI). Black and green dashed lines represent the thresholds of dengue and yellow fever transmission respectively defined by Pan American Health Organization and WHO. 
Table 1. Type of containers associated with the infestation of immature stages of Ae. aegypti and Ae. albopictus in Yaoundé.

\begin{tabular}{|c|c|c|c|c|c|c|c|c|c|c|}
\hline \multirow[b]{3}{*}{ Boroughs } & & \multicolumn{9}{|c|}{ Type of Containers } \\
\hline & & \multicolumn{3}{|c|}{ Domestic } & \multicolumn{4}{|c|}{ Peri-Domestic } & \multirow[t]{2}{*}{ Natural ${ }^{* *}$} & \multirow[t]{2}{*}{ Total } \\
\hline & & Watering Place & Flowerpots & Storage Containers & Used Tyres & Discarded Tanks & Car Wrecks & Miscellaneous * & & \\
\hline \multirow{5}{*}{ Yaoundé I } & $\mathrm{N}$ & 3 & 4 & 15 & 23 & 52 & 2 & 12 & 1 & 112 \\
\hline & $\%$ Positive & 33.3 & 25 & 53.3 & 47.8 & 38.5 & 50 & 58.3 & 0 & 4.4 \\
\hline & $\%$ Ae. albopictus only & 0 & 100 & 37.5 & 72.7 & 55 & 100 & 85.7 & 0 & 61.2 \\
\hline & $\%$ Ae. aegypti only & 0 & 0 & 0 & 9.1 & 5 & 0 & 0 & 0 & 4.1 \\
\hline & $\%$ Mixed & 100 & 0 & 62.5 & 18.2 & 40 & 0 & 14.3 & 0 & 34.7 \\
\hline \multirow{5}{*}{ Yaoundé II } & $\mathbf{N}$ & 0 & 9 & 24 & 21 & 34 & 3 & 6 & & 97 \\
\hline & $\%$ Positive & 0 & 0 & 12.5 & 66.7 & 23.5 & 33.3 & 66.7 & & 3.1 \\
\hline & $\%$ Ae. albopictus only & 0 & 0 & 0 & 42.9 & 62.5 & 0 & 25 & 0 & 40 \\
\hline & $\%$ Ae. aegypti only & 0 & 0 & 0 & 7.1 & 0 & 0 & 0 & 0 & 3.3 \\
\hline & $\%$ Mixed & 0 & 0 & 100 & 50 & 37.5 & 100 & 75 & 0 & 56.7 \\
\hline \multirow{5}{*}{ Yaoundé III } & $\mathrm{N}$ & 1 & 1 & 25 & 13 & 119 & 2 & 9 & 7 & 177 \\
\hline & $\%$ Positive & 0 & 100 & 28 & 30.8 & 25.2 & 100 & 44.4 & 28.6 & 2.8 \\
\hline & $\%$ Ae. albopictus only & 0 & 100 & 57.1 & 75 & 50 & 50 & 25 & 50 & 52 \\
\hline & $\%$ Ae. aegypti only & 0 & 0 & 14.3 & 25 & 10 & 50 & 25 & 0 & 14 \\
\hline & $\%$ Mixed & 0 & 0 & 28.6 & 0 & 40 & 0 & 50 & 50 & 34 \\
\hline \multirow{5}{*}{ Yaoundé IV } & $\mathrm{N}$ & 0 & 4 & 6 & 14 & 59 & 1 & 6 & 0 & 90 \\
\hline & $\%$ Positive & 0 & 50 & 33.3 & 57.1 & 32.2 & 0 & 83.3 & 0 & 4 \\
\hline & $\%$ Ae. albopictus only & 0 & 100 & 50 & 25 & 42.1 & 0 & 40 & 0 & 41.7 \\
\hline & $\%$ Ae. aegypti only & 0 & 0 & 0 & 0 & 10.5 & 0 & 0 & 0 & 5.6 \\
\hline & $\%$ Mixed & 0 & 0 & 50 & 75 & 47.4 & 0 & 60 & 0 & 52.8 \\
\hline \multirow{5}{*}{ Yaoundé V } & $\mathrm{N}$ & 5 & 1 & 19 & 11 & 45 & 9 & 7 & 3 & 100 \\
\hline & $\%$ Positive & 60 & 100 & 47.4 & 54.6 & 44.4 & 44.4 & 42.9 & 66.7 & 4.8 \\
\hline & $\%$ Ae. albopictus only & 0 & 100 & 66.7 & 50 & 60 & 50 & 0 & 50 & 52.1 \\
\hline & $\%$ Ae. aegypti only & 66.7 & 0 & 0 & 0 & 15 & 0 & 0 & 50 & 12.5 \\
\hline & $\%$ Mixed & 33.3 & 0 & 33.3 & 50 & 25 & 50 & 100 & 0 & 35.4 \\
\hline \multirow{5}{*}{ Yaoundé VI } & $\mathbf{N}$ & 0 & 2 & 3 & 27 & 77 & 3 & 20 & 3 & 135 \\
\hline & $\%$ Positive & 0 & 0 & 0 & 55.6 & 31.2 & 0 & 60 & 0 & 3.8 \\
\hline & $\%$ Ae. albopictus only & 0 & 0 & 0 & 86.7 & 70.8 & 0 & 66.7 & 0 & 74.5 \\
\hline & $\%$ Ae. aegypti only & 0 & 0 & 0 & 6.7 & 12.5 & 0 & 16.7 & 0 & 11.8 \\
\hline & $\%$ Mixed & 0 & 0 & 0 & 6.7 & 16.7 & 0 & 16.7 & 0 & 13.7 \\
\hline \multirow{5}{*}{$\begin{array}{c}\text { Yaoundé } \\
\text { VII }\end{array}$} & $\mathrm{N}$ & 8 & 5 & 30 & 62 & 119 & 3 & 15 & 2 & 244 \\
\hline & $\%$ Positive & 25 & 40 & 10 & 48.4 & 37 & 100 & 66.7 & 100 & 3.9 \\
\hline & $\%$ Ae. albopictus only & 0 & 50 & 33.3 & 56.7 & 15.9 & 33.33 & 30 & 50 & 32.3 \\
\hline & $\%$ Ae. aegypti only & 0 & 0 & 0 & 0 & 25 & 0 & 30 & 50 & 15.6 \\
\hline & $\%$ Mixed & 100 & 50 & 66.7 & 43.3 & 59.1 & 66.67 & 40 & 0 & 52.1 \\
\hline \multirow{5}{*}{ Total } & $\mathbf{N}$ & 17 & 26 & 122 & 171 & 505 & 23 & 75 & 16 & 955 \\
\hline & $\%$ Positive & 35.3 & 26.9 & 26.2 & 51.5 & 32.7 & 47.83 & 60 & 37.5 & 37.7 \\
\hline & $\%$ Ae. albopictus only & 0 & 85.7 & 46.9 & 59.1 & 45.5 & 45.45 & 46.7 & 50 & 49.2 \\
\hline & $\%$ Ae. aegypti only & 33.3 & 0 & 3.1 & 4.6 & 13.9 & 9.1 & 13.33 & 33.3 & 10.8 \\
\hline & $\%$ Mixed & 66.7 & 14.3 & 50 & 36.4 & 40.6 & 45.45 & 40 & 16.67 & 40 \\
\hline
\end{tabular}

$\mathrm{N}$, total number of potential containers prospected; \% Positive, percentage of containers infested with immature stages of Ae. albopictus and/or Ae. aegypti; \% Ae. albopictus only, percentage of containers infested only with immature stages of Ae. albopictus; \% Ae. aegypti only, percentage of containers infested only with immature stages of Ae. aegypti; \% Mixed, percentage of containers infested with immature stages of Ae. aegypti and Ae. albopictus; *, Miscellaneous included mostly block holes, ground tarpaulin, roof gutters, motorcycle helmets and wrecks, debris of fridges and televisions; **, Natural included snail and coconut shells, tree and rock holes, and axils of plants. 
Furthermore, the pupae index (PI) and the pupae per person index (PPI) were computed revealing an overall PI of 503.1\% (95\%CI, 461.4-544.9\%) which varied significantly from $226.7 \%$ in Yaoundé II to $785.4 \%$ in Yaoundé VII (ANOVA, $\mathrm{F}=8.9, p<0.05$ ). The pupae index for Ae. albopictus was significantly higher than that of Ae. aegypti (ANOVA, $\mathrm{F}=9.05, p<0.01$ ) (Figure 2a). The mean PPI was 50.3\% (95\%CI, 48.8-51.8\%) with a significant difference observed between PPIs for Ae. albopictus (44.6\%, 95\%CI, 43.2-48.1\%) and Ae. aegypti (5.7\%, 95\%CI, 5.0-5.7\%) $(p<0.001)$ (Figure $2 b)$.
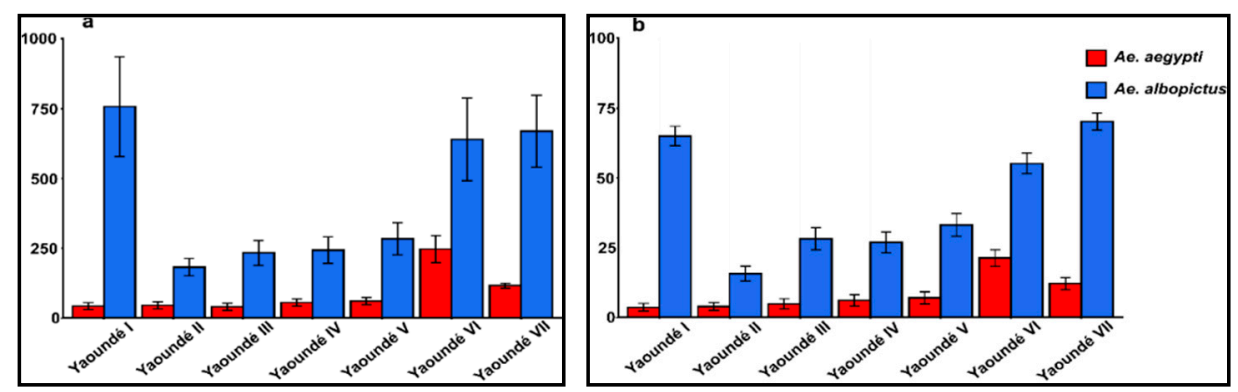

Figure 2. Pupae-based indices for Ae. albopictus and Ae. aegypti in Yaoundé; (a) pupae index (PI) and (b) pupae per person index (PPI).

\subsection{Container Prevalence and Preferences of Ae. albopictus and Ae. aegypti}

The various containers prospected were classified into three categories: domestic (watering places, flowerpots, and storage containers), peri-domestic (discarded tanks, used tyres, car wrecks, and miscellaneous), and natural (snail and coconut shells, tree and rock holes, and axils of plants). Peri-domestic containers were the most prevalent and the most infested category with a prevalence of infestation of $76.2 \%$ and $13.6 \%$ for Ae. albopictus and Ae. aegypti respectively (Table 2). The most productive containers for both species were discarded tanks and used tyres, although the distribution of immature stages and pupae were over-dispersed in all container types (Figure 3).

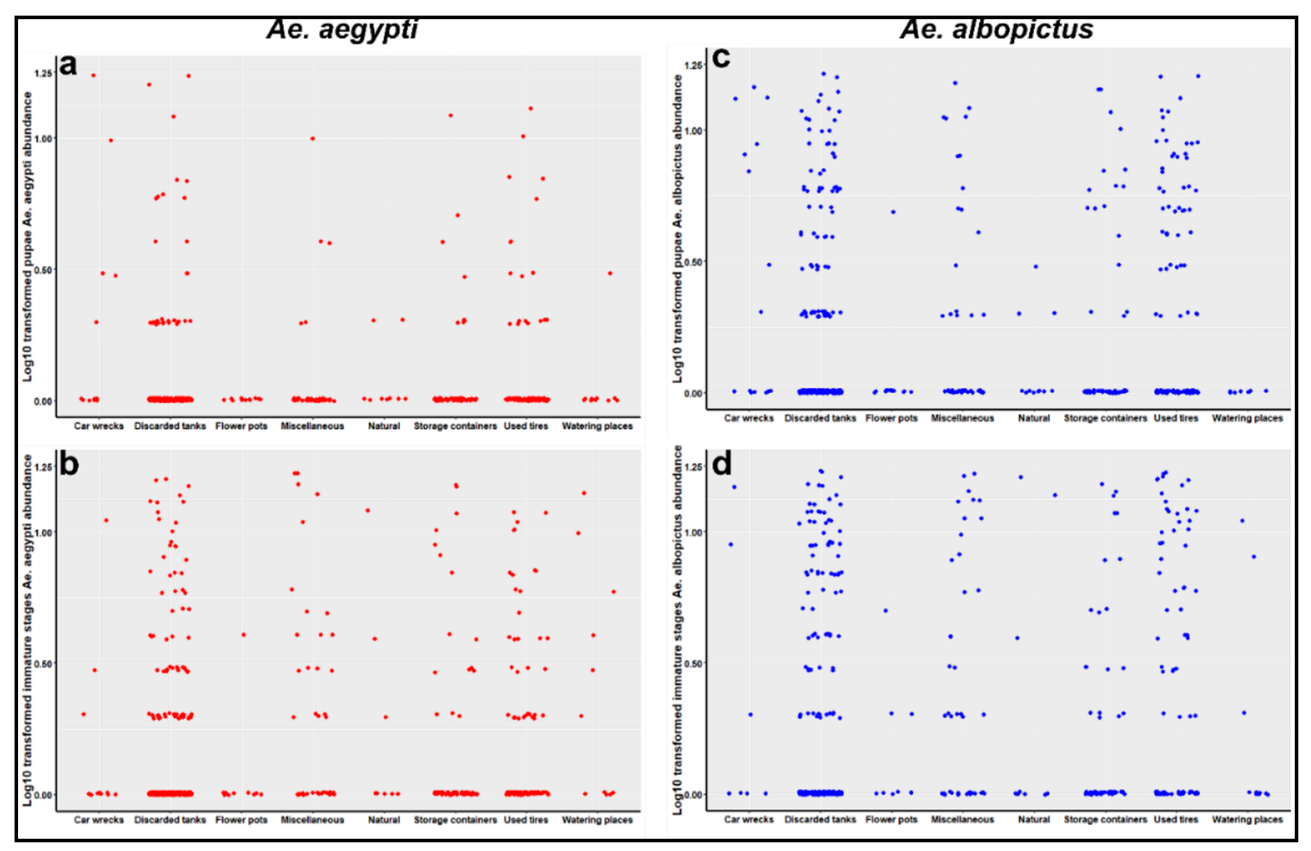

Figure 3. Total abundance of pupae and of pupae and larvae of Ae. aegypti $(\mathbf{a}, \mathbf{b})$ and Ae. albopictus $(\mathbf{c}, \mathbf{d})$, respectively, per type of container. Each dot represents the log10 transform of the abundance of containers infested by immature stages of Ae. albopictus and Ae. aegypti. 
Table 2. Level of infestation of Ae. albopictus and Ae. aegypti in different types of containers in Yaoundé.

\begin{tabular}{|c|c|c|c|c|c|c|c|c|c|}
\hline \multirow[b]{3}{*}{ Species } & \multicolumn{3}{|c|}{ Type of Containers } & \multirow{2}{*}{\multicolumn{4}{|c|}{ Peri-Domestic }} & \multirow{3}{*}{$\begin{array}{c}\text { Natural }{ }^{* *} \\
\text { Natural } \\
n(\%)\end{array}$} & \multirow{3}{*}{ Total $n(\%)$} \\
\hline & & Domestic & & & & & & & \\
\hline & $\begin{array}{c}\text { Watering Places } \\
n(\%)\end{array}$ & $\begin{array}{c}\text { Flowerpots } \\
n(\%)\end{array}$ & $\begin{array}{c}\text { Storage Containers } \\
n(\%)\end{array}$ & $\begin{array}{c}\text { Used Tyres } \\
n(\%)\end{array}$ & $\begin{array}{c}\text { Discarded Tanks } \\
n(\%)\end{array}$ & $\begin{array}{c}\text { Car Wrecks } \\
n(\%)\end{array}$ & $\begin{array}{c}\text { Miscellaneous * } \\
n(\%)\end{array}$ & & \\
\hline Ae. albopictus & $42(0.4)$ & $176(1.6)$ & $654(6.1)$ & $2763(25.6)$ & 4008 (37.1) & $482(4.5)$ & $982(9.1)$ & $68(0.6)$ & $9175(85)$ \\
\hline Ae. aegypti & $33(0.3)$ & $3(0.03)$ & $105(1)$ & $214(2)$ & $930(8.6)$ & $105(1)$ & $221(2.1)$ & $15(0.2)$ & $1626(15)$ \\
\hline Total & $75(0.7)$ & $179(1.7)$ & $759(7)$ & 2977 (27.6) & 4938 (45.7) & $587(5.4)$ & $1203(11.1)$ & $83(0.8)$ & $10,801(100)$ \\
\hline
\end{tabular}




\subsection{Environmental Characteristics Influencing the Presence of Aedes Species}

The analysis revealed that the presence of immature stages of Ae. aegypti and Ae. albopictus was positively associated with the presence of plant debris inside the container and water with organic materials $(p<0.01)$. The presence of immature stages of Ae. aegypti and Ae. albopictus was also associated with flowerpots and used tyres, respectively $(p<0.05)$ (Table 3$)$. The presence of Ae. albopictus pupae were also associated with containers of low capacity and containers made of rubber $(p<0.05)$, while the presence of Ae. aegypti pupae was associated with containers at a high distance from the ground $(p<0.05)$ (Table 3$)$.

\subsection{Spatial Distribution of Immature Stages of Ae. albopictus and Ae. aegypti}

A total of 10,801 specimens of Ae. albopictus and/or Ae. aegypti were identified after adults emerged, encompassing $84.95 \%$ Ae. albopictus and $15.05 \%$ Ae. aegypti (Table 2). The spatial distribution of the two species showed that both Aedes species were found across Yaoundé with a significant prevalence of Ae. albopictus in the suburb as well as downtown $(p<0.001)$, suggesting the efficient expansion and competitive advantage of this species. However, in the rural area no significant difference was found between the two Aedes species $(p>0.05)$, although Ae. aegypti seemed dominant. Indeed, Ae. albopictus was significantly more prevalent in almost all the neighbourhoods than Ae. aegypti $(p<0.05)$, except in Afanoyoa II and Eyang (two rural areas) where Ae. aegypti was significantly more prevalent $(p<0.001)$ (Table S1, Figure 4 and Figure S1).

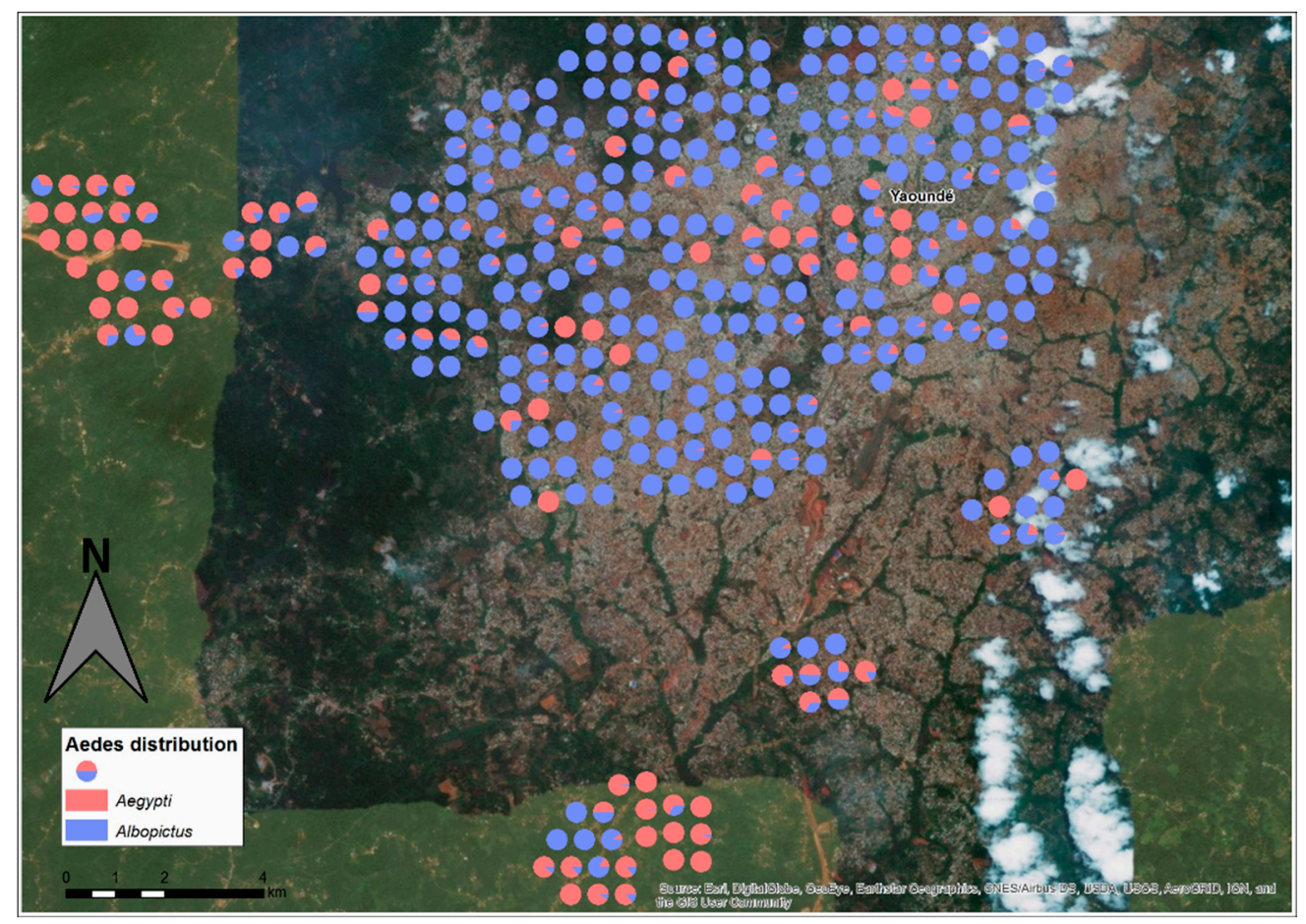

Figure 4. Spatial distribution of Aedes albopictus and Aedes aegypti in Yaoundé city. Each pie chart represents a positive container with the proportion of Ae. albopictus and Ae. aegypti. It is clearly observed that Ae. albopictus (in blue) is predominant in downtown and suburban areas whereas Ae. aegypti (in red) is predominant in rural areas, although it is present in some parts of the downtown areas. 
Table 3. Environmental characteristics of containers associated with the presence of pupae and larvae and/or pupae of Ae. albopictus and Ae. aegypti.

\begin{tabular}{|c|c|c|c|c|c|c|c|c|c|c|c|}
\hline & & \multicolumn{5}{|c|}{ Pupae } & \multicolumn{5}{|c|}{ Larvae and Pupae } \\
\hline & & \multirow[b]{2}{*}{ Number } & \multicolumn{2}{|r|}{ Ae. aegypti } & \multicolumn{2}{|c|}{ Ae. albopictus } & \multirow[b]{2}{*}{ Number } & \multicolumn{2}{|c|}{ Ae. aegypti } & \multicolumn{2}{|c|}{ Ae. albopictus } \\
\hline \multicolumn{2}{|c|}{ Categories } & & $\%$ & OR (CI 95\%) & $\%$ & OR (CI 95\%) & & $\%$ & OR (CI 95\%) & $\%$ & OR (CI 95\%) \\
\hline \multirow[t]{2}{*}{$\begin{array}{c}\text { Distance to the nearest } \\
\text { building }(\mathrm{m})\end{array}$} & $\begin{array}{l}\text { medium [5-20] } \\
\text { low }(<5)\end{array}$ & $\begin{array}{c}70 \\
163\end{array}$ & $\begin{array}{l}27.8 \\
66.7\end{array}$ & $\begin{array}{l}\operatorname{Ref}_{1} \\
1(0.5-2.3)\end{array}$ & $\begin{array}{l}29.9 \\
69.2\end{array}$ & $\begin{array}{l}\operatorname{Ref}_{1} \\
1(0.7-1.4)\end{array}$ & $\begin{array}{l}133 \\
272\end{array}$ & $\begin{array}{l}33.3 \\
60.6\end{array}$ & $\begin{array}{c}\text { Ref } \\
0.8(0.5-1.1)\end{array}$ & $\begin{array}{c}31 \\
66.9\end{array}$ & $\begin{array}{c}\text { Ref } \\
0.9(0.7-1.2)\end{array}$ \\
\hline & high $(>20)$ & 4 & 5.6 & $2.2(0.3-8.8)$ & 1 & $0.3(0.1-1)$ & 14 & 6.1 & $2.3(0.9-5.3)$ & 2.1 & $0.6(0.2-1.5)$ \\
\hline \multirow{2}{*}{$\begin{array}{l}\text { Distance to the nearest plant } \\
\qquad(\mathrm{m})\end{array}$} & $\begin{array}{l}\text { medium }[5-20] \\
\text { low }(<5)\end{array}$ & $\begin{array}{c}24 \\
211\end{array}$ & $\begin{array}{l}13.9 \\
86.1\end{array}$ & $\begin{array}{c}\text { Ref } \\
0.7(0.3-2.1)\end{array}$ & $\begin{array}{r}9.5 \\
89.6\end{array}$ & $\begin{array}{c}\text { Ref } \\
1.1(0.7-1.9)\end{array}$ & $\begin{array}{l}36 \\
381\end{array}$ & $\begin{array}{c}6.8 \\
93.2\end{array}$ & $\begin{array}{c}\text { Ref } \\
16(08-36)\end{array}$ & $\begin{array}{r}9.4 \\
899\end{array}$ & Ref \\
\hline & high $(>20)$ & 2 & & $0.00\left(\mathrm{NA}-1.6 \times 10^{17}\right)$ & 1 & $2.7(0.3-17.4)$ & 2 & & $0\left(\mathrm{NA}-2.6 \times 10^{23}\right)$ & 0.7 & $1.7(0.2-10.8)$ \\
\hline Distance to the ground (m) & $\begin{array}{l}\text { medium [1-3] } \\
\text { high [3-5] }\end{array}$ & $\begin{array}{c}21 \\
2\end{array}$ & $\begin{array}{l}5.6 \\
2.8\end{array}$ & $\begin{array}{c}\text { Ref } \\
21.5(0-3631) *\end{array}$ & 9.5 & $\begin{array}{c}\text { Ref } \\
18(01-20)\end{array}$ & $\begin{array}{c}42 \\
4\end{array}$ & 10.6 & $\begin{array}{c}\text { Ref } \\
106(1-236.8)\end{array}$ & 9.8 & $\begin{array}{c}\text { Ref } \\
43(04-94.5)\end{array}$ \\
\hline \multirow{4}{*}{ Sun exposure } & low $(<1)$ & 214 & 91.7 & $1.7(0.5-10.6)$ & 90 & $1(0.6-1.7)$ & 373 & 87.9 & $0.8(0.5-1.6)$ & 89.5 & $0.9(0.6-1.5)$ \\
\hline & partially shaded & 104 & 33.3 & Ref & 45.8 & Ref & 186 & 40.9 & Ref & 46 & Ref \\
\hline & exposed & 94 & 47.2 & $2(0.9-4.3)$ & 38.3 & $1.2(0.8-1.7)$ & 170 & 44.7 & $1.6(1.1-2.4)$ * & 38.7 & $1.20(0.9-1.6)$ \\
\hline & shaded & 39 & 19.4 & $1.8(0.7-4.7)$ & 15.9 & $1.1(0.7-1.7)$ & 63 & 14.4 & $1.1(0.6-1.9)$ & 15.3 & $1.04(0.7-1.6)$ \\
\hline \multirow[t]{5}{*}{ Material } & miscellaneous & 12 & 2.8 & Ref & 5.5 & Ref & 25 & 5.3 & Ref & 6.3 & Ref \\
\hline & rubber & 68 & 27.8 & $3.8(0.7-69.6)$ & 28.9 & $2.6(1.2-5.1) *$ & 101 & 16.7 & $1.2(0.5-3)$ & 27.5 & $2.1(1.1-4) *$ \\
\hline & metal & 28 & 8.3 & $1.5(0.2-29.9)$ & 12.4 & $1.13(0.5-2.6)$ & 49 & 12.9 & $1.2(0.5-3.3)$ & 11.1 & $0.8(0.4-1.6)$ \\
\hline & natural & 2 & & $0\left(0-3.2 \times 10^{11}\right)$ & 1 & $1.3(0.2-6.3)$ & 2 & & 0 & 0.7 & $0.7(0.1-3.2)$ \\
\hline & plastic & 127 & 61.1 & $2.3(0.5-42.1)$ & 52.2 & $1(0.51-2.05)$ & 242 & 65.2 & $1.3(0.6-3.3)$ & 54.4 & $0.9(0.5-1.6)$ \\
\hline \multirow{4}{*}{ Capacity of the container (L) } & high [20-50] & 70 & 30.6 & Ref & 29.4 & Ref & 113 & 22 & Ref & 29.3 & Ref \\
\hline & medium [5-20] & 82 & 38.9 & $0.86(0.4-2)$ & 33.8 & $0.7(0.5-1.1)$ & 138 & 29.5 & $0.9(0.5-1.5)$ & 34.5 & $0.7(0.5-1)$ \\
\hline & low $<5$ & 72 & 25 & $0.5(0.2-1.3)$ & 31.3 & $0.7(0.4-1)^{*}$ & 144 & 42.4 & $1.4(0.8-2.2)$ & 30.7 & $0.6(0.4-0.9)^{*}$ \\
\hline & very high $>50$ & 13 & 5.6 & $0.6(0.1-2.5)$ & 5.5 & $0.6(0.3-1.2)$ & 24 & 6.1 & $1(0.4-2.2)$ & 5.6 & $0.6(0.3-1.1)$ \\
\hline \multirow{2}{*}{ Volume of water (L) } & high [20-50] & 5 & & Ref & 2.5 & Ref & 9 & 1.5 & Ref & 2.4 & Ref \\
\hline & medium [5-20] & 42 & 16.7 & $4 \times 10^{6}\left(0-3.4 \times 10^{168}\right)$ & 17.9 & $1.3(0.5-4.2)$ & 72 & 17.4 & $2.2(0.6-14)$ & 17.1 & $1.3(0.6-3.5)$ \\
\hline \multirow{4}{*}{ Origin of water } & low $<5$ & 188 & 83.3 & $4.9 \times 10^{6}\left(0-4.1 \times 10^{166}\right)$ & 78.9 & $1.5(0.6-4.3)$ & 335 & 80.3 & $2.5(0.7-15.5)$ & 79.8 & $1.6(0.7-4)$ \\
\hline & very high > 50 & 2 & & $1\left(0-8.7 \times 10^{15}\right)$ & 1 & $0.5(0.1-2.5)$ & 3 & 0.8 & $0.7(0-7.3)$ & 0.7 & $0.3(0.1-1.5)$ \\
\hline & well & 1 & & Ref & 0.5 & Ref & 2 & 0 & Ref & 0.7 & Ref \\
\hline & rain & 227 & 97.2 & $6.1 \times 10^{5}(0-\mathrm{NA})$ & 95.5 & $1.1(0.2-20.6)$ & 407 & 98.5 & $942714.93(0-\mathrm{NA})$ & 96.5 & $0.6(0.1-4.9)$ \\
\hline \multirow{5}{*}{ Quality of water } & tap & 9 & 2.8 & $6.5 \times 10^{5}\left(0-9.5 \times 10^{164}\right)$ & 4 & $1.9(0.2-40)$ & 10 & 1.5 & $\begin{array}{l}5 \times 10^{5}(486-9.1 \times \\
1116)\end{array}$ & 2.8 & $0.7(0.1-6.2)$ \\
\hline & urine & 0 & & $1\left(0-2.2 \times 10^{24}\right)$ & & $0\left(\mathrm{NA}-4.6 \times 10^{34}\right)$ & 0 & & $1\left(0-1.7 \times 10^{7}\right)$ & & $0\left(\mathrm{NA}-3 \times 10^{41}\right)$ \\
\hline & clear & 132 & 55.6 & Ref & 55.7 & Ref & 243 & 59.1 & Ref & 57.5 & Ref \\
\hline & polluted & 6 & 2.8 & $0.3(0.02-1.56)$ & 2.5 & $0.3(0.1-0.6) *$ & 10 & 1.5 & $0.2(0-0.5)$ * & 2.8 & $0.3(0.1-0.5)$ * \\
\hline & turbid & 99 & 41.7 & $2(1-4)^{*}$ & 41.8 & $2.4(1.8-3.4)$ * & 166 & 39.4 & $1.9(1.30-2.8)^{*}$ & 39.7 & $2.5(1.8-3.4)^{*}$ \\
\hline \multirow{2}{*}{ Presence of plant debris } & no & 88 & 38.9 & Ref & 36.8 & Ref & 167 & 39.4 & Ref & 40.1 & Ref \\
\hline & yes & 149 & 61.1 & $1.9(1-3.9)$ & 63.2 & $2.5(1.8-3.5)$ * & 252 & 60.6 & $2.1(1.41-3)^{*}$ & 59.9 & $2.3(1.8-3.1)^{*}$ \\
\hline \multirow{5}{*}{ Type of container } & watering places & 1 & 2.8 & Ref & & Ref & 8 & 3.8 & Ref & 1 & Ref \\
\hline & miscellaneous & 25 & 8.3 & $0.7(0.1-14)$ & 10.9 & NA & 51 & 14.4 & $0.8(0.3-2.8)$ & 11.1 & $3.5(1-16)$ \\
\hline & & 14 & 11.1 & $3.4(0.4-69.5)$ & 5 & NA & 14 & 3.8 & $0.7(0.2-2.9)$ & 3.1 & $3(0.7-15.7)$ \\
\hline & natural & 3 & & $0\left(0-3.9 \times 10^{27}\right)$ & 1.5 & NA & 6 & 1.5 & $0.3(0-1.9)$ & 1.4 & $1.6(0.3-9.3)$ \\
\hline & used tyres & 69 & 27.8 & $1(0.2-18.8)$ & 29.4 & NA & 103 & 17.4 & $0.4(0.1-1.3)$ & 27.9 & $4.1(1.3-18.3)$ * \\
\hline
\end{tabular}


Table 3. Cont

\begin{tabular}{|c|c|c|c|c|c|c|c|c|c|c|c|}
\hline & & \multicolumn{5}{|c|}{ Pupae } & \multicolumn{5}{|c|}{ Larvae and Pupae } \\
\hline & & & & Ae. aegypti & & bopictus & & & aegypti & & bopictus \\
\hline \multicolumn{2}{|c|}{ Categories } & Number & $\%$ & OR (CI 95\%) & $\%$ & OR (CI 95\%) & Number & $\%$ & OR (CI 95\%) & $\%$ & OR (CI 95\%) \\
\hline \multirow{6}{*}{ Colour } & flowerpots & 2 & & $0\left(0-1.4 \times 10^{20}\right)$ & 1 & NA & 6 & 0.8 & $0.1(0-0.7) *$ & 1.7 & $1.1(0.2-6.1)$ \\
\hline & discarded tanks & 101 & 38.9 & $0.46(0.08-8.51)$ & 43.3 & NA & 191 & 47.7 & $0.34(0.12-1.10)$ & 44.6 & $1.6(0.5-7)$ \\
\hline & storage containers & 22 & 11.1 & $0.5(0.1-11)$ & 9 & NA & 40 & 10.6 & $0.3(0.1-1.1)$ & 9.1 & $1.3(0.4-5.8)$ \\
\hline & mixed & 31 & 2.8 & Ref & 14.9 & Ref & 69 & 19.7 & Ref & 15 & Ref \\
\hline & single & 184 & 83.3 & $7.3(1.6-131)$ & 76.6 & $1.3(0.8-2)$ & 304 & 66.7 & $0.8(0.5-1.3)$ & 75.3 & $1.3(0.9-1.9)$ \\
\hline & transparent & 22 & 13.9 & $6.6(1.1-127.3)$ & 8.5 & $0.7(0.4-1.3)$ & 46 & 13.6 & $0.9(0.4-1.7)$ & 9.8 & $0.8(0.5-1.4)$ \\
\hline \multirow[t]{3}{*}{ Mobility of the container } & $\begin{array}{c}\text { fixed } \\
\text { lixhed }\end{array}$ & 6 & & $\begin{array}{c}\text { Ref } \\
16 \times 10^{6}(0-N)(1)\end{array}$ & 3 & Ref & $\begin{array}{c}8 \\
395\end{array}$ & $\begin{array}{l}1.5 \\
94 .\end{array}$ & Ref & $\begin{array}{c}2.1 \\
94.1\end{array}$ & Ref \\
\hline & lightweight & 222 & 94.4 & $1.6 \times 10^{6}(0-\mathrm{NA})$ & 93.5 & $0.6(0.2-2.2)$ & 395 & 94.7 & $0.9(0.2-5.8)$ & 94.1 & $0.5(0.2-1.6)$ \\
\hline & heavyweight & 9 & 5.6 & $2.9 \times 10^{6}\left(0-5.9 \times 10^{164}\right)$ & 3.5 & $0.7(0.2-3)$ & 14 & 3.8 & $1.1(0.2-8.2)$ & 3.1 & $0.5(0.1-1.9)$ \\
\hline
\end{tabular}

OR, odds ratio; CI, confidence interval; *, significant association; NA, not applicable; Ref, comparator group to estimate the OR. 


\section{Discussion}

This study presented the current geographical distribution, the level of infestation, and the factors governing the presence of Ae. albopictus and Ae. aegypti in Yaoundé as well as the entomological risk for large arbovirus outbreaks based on Stegomyia indices. Our analysis confirmed the co-occurrence of both Ae. aegypti and Ae. albopictus across Yaoundé with a predominance of Ae. albopictus in downtown and suburban areas. This observation is in accordance with previous data collected in Yaoundé in 2007 highlighting the predominance of Ae. albopictus in this city [18]. A spot of Ae. aegypti persisting downtown matches the previous observations made in 2017 in the same city [13]. In fact, Ae. albopictus was first recorded in Cameroon in the early 2000s [11] and has rapidly colonized all human-domesticated environments in the southern part of the country $[33,34]$. The predominance of Ae. albopictus across Yaoundé confirms the competitive advantage of this species on the native species Ae. aegypti as was suspected previously [18]. These observations are consistent with other studies reported in several countries in the world in areas invaded by Ae. albopictus such as in Brazil [22,45], Florida [14,24], and Australia [26]. However, the mechanisms by which competition takes place are not well known, but some authors believe that it could happen at the pre-imaginal phase and that several factors such as temperature, precipitation, response to symbionts, predators, and chemical interferences that retard growth are the main drivers $[25,46]$. Also, other work has shown that the two species are able to mate in nature and that Ae. albopictus males effectively sterilize Ae. aegypti females [47-49]. The authors suggest that this form of mating interference, called satyrization, could explain the competitive displacement of resident Ae. aegypti by the invasive Ae. albopictus where they co-occur. Surprisingly, the coexistence of Ae. aegypti and Ae. albopictus was reported in Peninsular Florida (USA) two decades after competitive displacement, suggesting a resistance to mating interference [17]. The abundance of Ae. aegypti found in rural areas located in two different boroughs in Yaoundé could suggest a resistance to mating interference with Ae. albopictus among this population, which allows them to co-occur in this area, and further investigations are needed to elucidate. It is important to underline that this study was carried out during the raining season only, although it was demonstrated that seasonality can affect the pattern of abundance of Ae. aegypti and Ae. albopictus [19,50]. The variation in abundance between the two species would probably be due to the difference in the tolerance of desiccation of the eggs of both species [51]. However, previous data collected in Central Africa suggest that the variation in abundance between Ae. aegypti and Ae. albopictus depends on the difference of time between the rainy season and the dry season among locations [13]. Surprisingly, no immature stages were found in the Briquetrie (Muslim) neighbourhood in the houses surveyed; however, residents notified us of the use of larvicide to treat the potential breeding sites. Further studies including socio-anthropological aspects are needed to elucidate further.

Overall, the immature stages of both Ae. aegypti and Ae. albopictus preferentially colonized peri-domestic containers, particularly discarded tanks and used tyres. These observations are consistent with previous results reported in Central Africa $[13,19]$. However, the opposite situation was found in other parts of the world, particularly in Asia, where domestic containers such as water storage tanks represent the bulk of infested containers for Ae. aegypti [52]. Interestingly, it has been clearly established that in major unplanned urban cities, improved waste management through the physical removal of used containers reduces the quantity of mosquito breeding sites and thus decreases Aedes densities [1,53,54].

Both species breed in the same type of container, notably flowerpots, discarded tanks, used tyres, and car wrecks filled with turbid water, and are associated with plant debris inside. These outcomes highlight the impact of micro-environmental factors on the presence of Aedes spp. inside breeding sites. In fact, the presence of organic matters inside the larval habitats could serve as food resources $[19,55]$ or a micro-habitat to hide and avoid predators [55,56]. The sympatric situations found in certain containers suggest possible competition for resources and other ecological interactions in the larval stage which may influence physiological characteristics like body size and wing length, and thus affect adult vector competence for arboviruses [54,57]. 
Overall, the infestation indices were higher compared to the thresholds established by WHO for dengue virus (DENV) [43] and yellow fever virus (YFV) [44] transmission. In fact, estimated risk values suggest that Yaoundé is at high potential risk of dengue outbreaks for both species and a high potential risk of yellow fever outbreaks for Ae. albopictus. These results highlight a higher potential of human exposure to the bites of Ae. aegypti and/or Ae. albopictus females in Yaoundé depending to the borough or neighbourhood. Indeed, previous studies based on Stegomyia indices have shown that high indices coincided with dengue outbreaks in some African countries such as Kenya [58], Ethiopia [59], and Tanzania [60]. The higher indices for Ae. albopictus compared to those of Ae. aegypti previously recorded in 2007 in Yaoundé [18] show a stability of the potential risk in this city. Such potential risk is also similar to that observed in other central African cities such as Bangui in the Central African Republic [19]. Interestingly, it was recently demonstrated that Ae. aegypti and Ae. albopictus populations from Yaoundé are able to transmit DENV [41] and Zika virus (ZIKV) [42], further increasing such potential risk. The same was observed of the Ae. aegypti population for YFV [40]. Additional studies including a dynamic of abundance of each species depending on the season and trophic behaviour of each species are required to establish the epidemiological importance of each species.

\section{Materials and Methods}

\subsection{Ethics Statement}

Ethical clearance $N^{\circ}$ 2017/05/911/CE/CNERSH/SP was delivered by the Cameroonian National Ethics Committee for Human Health Research for this study. An oral consent form was obtained from the head or representative of each household prior to the survey.

\subsection{Study Sites}

The study was carried out in Yaoundé $\left(03^{\circ} 51^{\prime} \mathrm{N}, 11^{\circ} 30^{\prime} \mathrm{E}\right)$, the capital city of Cameroon, one of the most urbanized cities in the country with around 15,900 ha of urbanized areas divided into seven boroughs [61] (Figure 5). The city is $800 \mathrm{~m}$ above sea level and the environment is characterized by gentle rolling chains of hills, numerous valleys, and wetlands, and the remnants of the forest around these areas are being rapidly destroyed. The climate is sub-equatorial Guinean (mean annual rainfall and temperature of $1600 \mathrm{~mm}$ and $25^{\circ} \mathrm{C}$, respectively) with two distinct rainy seasons, the first extending from March to June and the second from September to November [62]. The agglomeration consists of more administrative and commercial structures discreetly distributed throughout the city [63]. From 2000 to 2014, the population has substantially doubled, reaching 2.6 million. This rapid growth has brought about an increase in the need for space and settlement which are reflected by the growing extension of houses in the suburbs of the city, peripheral neighbourhoods being mostly populated by waves of recent arrivals [61,63].

\subsection{Study Design}

A cross-sectional survey was carried out in Yaoundé, in April-May 2018, corresponding to the rainy season. Entomological surveys were undertaken in clusters of houses sampled randomly, each cluster consisting of 15 houses per neighbourhood in each of the seven boroughs (Figure 1). Each selected house was geo-referenced with a Global Positioning System (GPS, Garmin eTrex ${ }^{\circledR}$ ) and inspected to record all natural and artificial water-holding containers (potential containers) and those containing at least one immature stage (larvae or pupae) of Aedes (positive containers). Positive and potential containers were geo-referenced, and the nature, mobility, material, and colour of the container, the distance between the container and the nearest building, the nearest plant and the ground, the container volume, the volume, source (rain, tap water, drilling water), and quality (clear, tinted) of water, the presence of plant debris inside the container, the presence of vegetation around the container, sun exposure, and the number of inhabitants per house were recorded. Potential containers were classified into three categories, domestic, peri-domestic, and natural based on the source and the use 
of the water. Domestic containers (e.g., storage containers) were defined as human-filled receptacles, whereas peri-domestic (e.g., used tyres and discarded tanks) and natural (e.g., tree and rock holes) containers were those filled by rain or humans. Whenever they were present, larvae and/or pupae were collected and returned to the insectarium at the Centre for Research in Infectious Diseases and isolated from predators such as Culex tigripes and Toxorynchites sp. larvae. For each container, pupae were isolated from larvae, counted, and reared to adults. Larvae were also reared to adults. The adults that emerged were identified using morphological identification keys $[64,65]$. The number of immature stages of Ae. albopictus and Ae. aegypti was estimated from the proportion of emerging adults of each species.

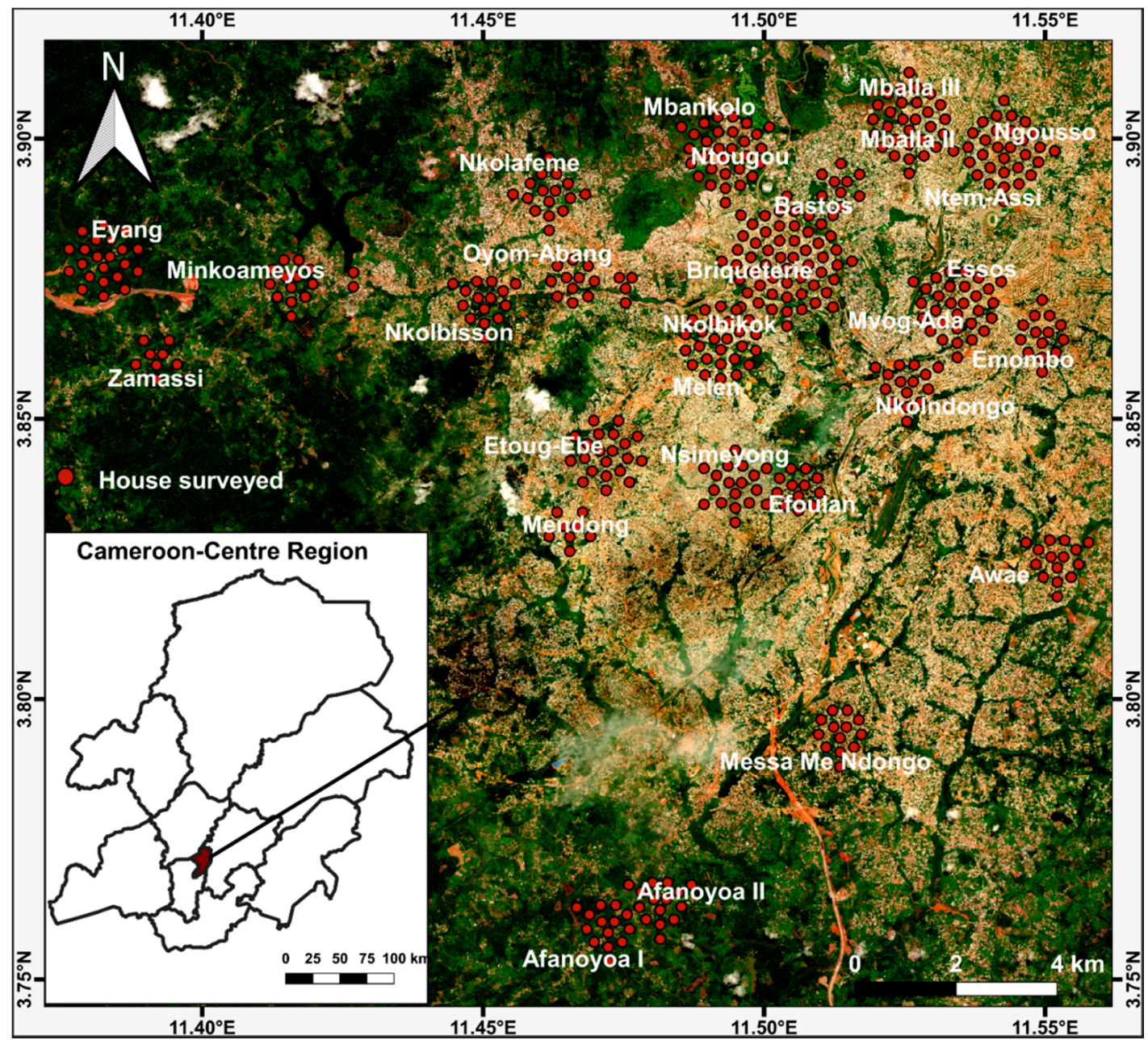

Figure 5. Geographical distribution of prospected houses in Yaoundé. Immature stages were sampled in cluster of 15 houses in each neighbourhood.

\subsection{Entomological Indices}

The level of infestation of Ae. aegypti and Ae. albopictus including the house index (HI, percentage of houses infested with larvae and/or pupae), the Breteau index (BI, number of positive containers per 100 houses inspected), and the container index (CI, percentage of water-holding containers infested with larvae and/or pupae) was assessed. Estimated thresholds of $\mathrm{HI}, \mathrm{BI}$, and CI references have been established by WHO for dengue and yellow fever transmission. Whenever $\mathrm{HI}>35 \%$, BI $>50 \%$, and CI $>20 \%$, the city is considered at high potential risk of the urban transmission of YFV, whereas $\mathrm{HI}<4 \%$, $\mathrm{BI}<5 \%$, and $\mathrm{CI}<3 \%$ indicate that the city is considered at low potential risk of disease transmission [44]. Similarly, low HI $(<0.1 \%)$, medium HI $(0.1-5 \%)$, and high HI $(>5 \%)$ were established for potential dengue transmission [43]. Additional indices based on the presence or absence and 
number of pupae were assessed, including the pupal index (PI, number of pupae per 100 houses) and the pupal per person index (PPI, number of pupae per 100 persons). To evaluate the most productive container, we assessed the productivity index which is defined as the percentage of pupae per container type among the prospected containers [52,55].

\subsection{Data Analysis}

Categorical and numerical variables were expressed as proportions and means respectively. Different proportions and means were compared using exact binomial and ANOVA tests respectively. Several environmental characteristics were recorded and the distribution of each variable was observed. Type of container (eight categories), type of container material (five categories), colour of material (three categories), mobility of the container (three categories), sun exposure (three categories), quality of water inside the container (three categories), plant debris inside the container (two categories), and presence of immature stages were defined as categorical variables, and the number of inhabitants, distance to the nearest building, plant, and ground, volume of the container, and the number of immature stages were defined as numerical variables. The level of association between environmental characteristics and the presence of larvae and/or pupae of Ae. albopictus and Ae. aegypti was assessed using a binary logistic regression from the generalized linear model (GLM) function. All statistical analyses were performed with $\mathrm{R}$ version 3.5.2 and RStudio version 1.1.463 [66], and $p$-value $<0.05$ was considered statistically significant. The GPS coordinates of the neighbourhoods, prospected houses and positive containers of each species were projected onto maps with the open-source software QGIS [67].

\section{Conclusions}

This study highlights the predominance of Ae. albopictus over Ae. aegypti and emphasizes the existing risk of an arbovirus epidemic in Yaoundé. The results could help influence policies and contribute to the establishment of an arbovirus control program in Cameroon which is currently lacking.

Supplementary Materials: The following are available online at http://www.mdpi.com/2076-0817/9/6/491/s1, Figure S1: Spatial distribution of abundance of immature stages of Ae. albopictus and Ae. aegypti per neighbourhood in Yaoundé. Table S1: Prevalence of immature stages of Ae. albopictus and Ae. aegypti and chi-squared test comparison of different neighbourhoods of Yaoundé. Table S2: Estimated dengue and yellow fever transmission potential risk levels based on house (HI), Breteau (BI), and container (CI) indices in Yaoundé.

Author Contributions: Conceptualization, A.N.T., B.K., and C.S.W.; Methodology: A.N.T., A.P.Y., T.A.W.-B., and B.K.; Validation: B.K. and C.S.W.; Formal analysis, A.N.T., T.A.W.-B., and B.K.; Investigation, A.N.T., T.A.W.-B., A.P.Y., and B.K.; Resources: B.K. and F.N.; Data curation, B.K. and C.S.W.; Writing-original draft, A.N.T., B.K., and C.S.W.; Writing-review and editing: A.N.T., A.P.Y., T.A.W.-B., F.N., B.K., and C.S.W.; Visualization: A.N.T., B.K., and C.S.W.; Supervision, B.K., F.N., and C.S.W.; Project administration, B.K. and C.S.W.; Funding acquisition, B.K. and C.S.W. All authors have read and agreed to the published version of the manuscript.

Funding: This research was funded by a Wellcome Trust Training Fellowship in Public Health and Tropical Medicine, grant number 204862, awarded to B.K.

Acknowledgments: We are grateful to all the heads of household and the various communities for the given consent for the entomological survey and their collaboration during field collections respectively. Our gratitude goes equally to Tiago Canelas for his contribution to map designing.

Conflicts of Interest: The authors declare no conflict of interest. The funders had no role in the design of the study; in the collection, analyses, or interpretation of data; in the writing of the manuscript, or in the decision to publish the results.

\section{References}

1. WHO. Global Vector Control Response 2017-2030; World Health Organization: Geneva, Switzerland, 2017.

2. Leta, S.; Beyene, T.J.; De Clercq, E.M.; Amenu, K.; Kraemer, M.U.G.; Revie, C.W. Global risk mapping for major diseases transmitted by Aedes aegypti and Aedes albopictus. Int. J. Infect. Dis. 2018, 67, 25-35. [CrossRef] [PubMed] 
3. Moore, M.; Sylla, M.; Goss, L.; Burugu, M.W.; Sang, R.; Kamau, L.W.; Kenya, E.U.; Bosio, C.; Munoz Mde, L.; Sharakova, M.; et al. Dual African origins of global Aedes aegypti s.l. populations revealed by mitochondrial DNA. PLoS Negl. Trop. Dis. 2013, 7, 1-8. [CrossRef] [PubMed]

4. Mattingly, P.F. Genetical Aspects of the Aedes aegypti Problem. Ann. Trop. Med. Parasit. 1957, 51, $392-408$. [CrossRef] [PubMed]

5. Gratz, N.G. Critical review of the vector status of Aedes albopictus. Med. Vet. Entomol. 2004, 18, $225-227$. [CrossRef] [PubMed]

6. Enserink, M. A mosquito goes global. Science 2008, 320, 864-866. [CrossRef] [PubMed]

7. Juliano, S.A.; Lounibos, L.P. Ecology of invasive mosquitoes: Effects on resident species and human health. Ecol. Lett. 2005, 8, 558-574. [CrossRef]

8. Kraemer, M.U.; Sinka, M.E.; Duda, K.A.; Mylne, A.Q.; Shearer, F.M.; Barker, C.M.; Moore, C.G.; Carvalho, R.G.; Coelho, G.E.; Van Bortel, W.; et al. The global distribution of the arbovirus vectors Aedes aegypti and Ae. albopictus. Elife 2015, 4, e08347. [CrossRef]

9. Reiter, P. Aedes albopictus and the world of trade in used tires, 1988-1995: The shape of things to come. J. Am. Mosquito. Contr. 1998, 14, 83-94.

10. Paupy, C.; Delatte, H.; Bagny, L.; Corbel, V.; Fontenille, D. Aedes albopictus, an arbovirus vector: From the darkness to the light. Microbes Infect. 2009, 11, 1177-1185. [CrossRef]

11. Fontenille, D.; Toto, J.C. Aedes (Stegomyia) albopictus (Skuse), a Potential New Dengue Vector in Southern Cameroon. Emerg. Infect. Dis. 2001, 7, 1066-1067. [CrossRef]

12. Ngoagouni, C.; Kamgang, B.; Nakouné, E.; Paupy, C.; Kazanji, M. Invasion of Aedes albopictus (Diptera: Culicidae) into central Africa: What consequences for emerging diseases? Parasit. Vectors 2015, 8, 1-7. [CrossRef] [PubMed]

13. Kamgang, B.; Yougang, A.P.; Tchoupo, M.; Riveron, J.M.; Wondji, C. Temporal distribution and insecticide resistance profile of two major arbovirus vectors Aedes aegypti and Aedes albopictus in Yaounde, the capital city of Cameroon. Parasit. Vectors 2017, 10, 469. [CrossRef] [PubMed]

14. Braks, M.A.H.; Lourenco-De-Oliveira, R.; Juliano, S.A.; Honorio, N.A.; Lounibos, L.P. Convergent habitat segregation of Aedes aegypti and Aedes albopictus (Diptera: Culicidae) in Southeastern Brazil and Florida. Fac. Publ. Biol. Sci. 2003, 40, 13. [CrossRef] [PubMed]

15. Sivan, A.; Shriram, A.N.; Sunish, I.P.; Vidhya, P.T. Host-feeding pattern of Aedes aegypti and Aedes albopictus (Diptera: Culicidae) in heterogeneous landscapes of South Andaman, Andaman and Nicobar Islands, India. Parasitol. Res. 2015, 114, 3539-3546. [CrossRef] [PubMed]

16. Ponlawat, A.; Harrington, L.C. Blood Feeding Patterns of Aedes aegypti and Aedes albopictus in Thailand. J. Med. Entomol. 2005, 42, 844-849. [CrossRef]

17. Lounibos, L.P.; Bargielowski, I.; Carrasquilla, M.C.; Nishimura, N. Coexistence of Aedes aegypti and Aedes albopictus (Diptera: Culicidae) in Peninsular Florida Two Decades After Competitive Displacements. J. Med. Entomol. 2016, 53, 1385-1390. [CrossRef]

18. Kamgang, B.; Happi, J.Y.; Boisier, P.; Njiokou, F.; Herve, J.P.; Simard, F.; Paupy, C. Geographic and ecological distribution of the dengue and chikungunya virus vectors Aedes aegypti and Aedes albopictus in three major Cameroonian towns. Med. Vet. Entomol. 2010, 24, 10. [CrossRef]

19. Kamgang, B.; Ngoagouni, C.; Manirakiza, A.; Nakouné, E.; Paupy, C.; Kazanj, M. Temporal Patterns of Abundance of Aedes aegypti and Aedes albopictus (Diptera Culicidae) and Mitochondrial DNA analysis of Ae. albopictus in Central African Republic. PLoS Negl. Trop. Dis. 2013, 7, 12. [CrossRef]

20. Weetman, D.; Kamgang, B.; Badolo, A.; Moyes, C.L.; Shearer, F.M.; Coulibaly, M.; Pinto, J.; Lambrechts, L.; McCall, P.J. Aedes Mosquitoes and Aedes-borne arboviruses in Africa: Current and future threats. Int. J. Environ. Res. Public. Health 2018, 15, 220. [CrossRef]

21. O'Meara, G.F.; Evans, L.F., Jr.; Gettman Alan, D.; Cuda, J.P. Spread of Aedes albopictus and decline of Aedes aegypti in Florida. J. Med. Entomol. 1995, 32, 9.

22. Bracks, M.A.H.; Honorio, N.A.; Lounibos, L.P.; Lourenço-De-Oliveira, R.; Juliano, S.A. Interspecific competition between two invasive species of container mosquitoes, Aedes aegypti and Aedes albopictus (Diptera: Culicidae), in Brazil. Ann. Entomol. Soc. Am. 2004, 97, 130-139. [CrossRef]

23. Honório, N.A.; Da Costa Silva, W.; José Leite, P.; Gonçalves, J.M.; Lounibos, L.P.; Lourenço-de-Oliveira, R. Dispersal of Aedes aegypti and Aedes albopictus (Diptera: Culicidae) in an Urban Endemic Dengue Area in the State of Rio de Janeiro, Brazil. Mem. Inst. Oswaldo Cruz 2003, 98, 191-198. [CrossRef] [PubMed] 
24. Rey, J.R.; Nishimura, N.; Wagner, B.; Braks, M.A.H.; O'Connell, S.M.; Lounibos, L.P. Habitat segregation of mosquito Arbovirus in South Florida. J. Med. Entomol. 2006, 43, 7. [CrossRef]

25. Juliano, S.A.; Lounibos, L.P.; O'Meara, G.F. A field test for competitive effects of Aedes albopictus on A. aegypti in South Florida: Differences between sites of coexistence and exclusion. Oecologia 2004, 139, 19. [CrossRef]

26. Muzari, M.; Davis, J.; Bellwood, R.; Crunkhorn, B.; Gunn, E.; Sabatino, U.; Gair, R. Dominance of the tiger: The displacement of Aedes aegypti by Aedes albopictus in parts of the Torres Strait, Australia. Commun. Dis. Intell. 2019, 43. [CrossRef]

27. Bagny, L.; Delatte, H.; Quilici, S.; Fontenille, D. Progressive decrease in Aedes aegypti distribution in Reunion Island since the 1900s. J. Med. Entomol. 2009, 46, 1541-1545. [CrossRef]

28. Salvan, M.; Mouchet, J. Aedes albopictus et Aedes aegypti à l'île de la Reunion. Ann. Soc. Belg. Med. Trop. 1994, 74, 323-326.

29. Bagny Beilhe, L.; Arnoux, S.; Delatte, H.; Lajoie, G.; Fontenille, D. Spread of invasive Aedes albopictus and decline of resident Aedes aegypti in urban areas of Mayotte 2007-2010. Biol. Invasions 2012, 14, 1623-1633. [CrossRef]

30. Kamgang, B.; Wilson-Bahun, T.A.; Irving, H.; Kusimo, M.O.; Lenga, A.; Wondji, C.S. Geographical distribution of Aedes aegypti and Aedes albopictus (Diptera: Culicidae) and genetic diversity of invading population of Aedes albopictus in the Republic of the Congo. Wellcome Open Res. 2018, 3, 1-17. [CrossRef]

31. Seng, M.C.; Jute, N. Breeding of Aedes aegypti and Aedes albopictus in urban housing of Sibu town, Sarawak. Southeast Asian J. Trop. Med. Public Health 1994, 25, 543-548.

32. Chan, Y.C.; Chan, K.L.; Ho, B.C. Aedes aegypti and Aedes albopictus in Singapore city: Distribution and density. Bull. World Health Org. 1971, 44, 617-627. [PubMed]

33. Tedjou, A.N.; Kamgang, B.; Yougang, A.P.; Njiokou, F.; Wondji, C.S. Update on the geographical distribution and prevalence of Aedes aegypti and Aedes albopictus (Diptera: Culicidae), two major arbovirus vectors in Cameroon. PLoS Negl. Trop. Dis. 2019, 13, e0007137. [CrossRef] [PubMed]

34. Simard, F.; Nchoutpouen, E.; Toto, J.C.; Fontenille, D. Geographic Distribution and Breeding Site Preference of Aedes albopictus and Aedes aegypti (Diptera: Culicidae) in Cameroon, Central Africa. J. Med. Entomol. 2005, 42, 726-731. [CrossRef] [PubMed]

35. Tchuandom, S.B.; Tchadji, J.C.; Tchouangueu, T.F.; Biloa, M.Z.; Atabonkeng, E.P.; Fumba, M.I.M.; Massom, E.S.; Nchinda, G.; Kuiate, J.R. A cross-sectional study of acute dengue infection in paediatric clinics in Cameroon. BMC Public Health 2019, 19, 958. [CrossRef] [PubMed]

36. Nemg Simo, F.B.; Sado Yousseu, F.B.; Evouna Mbarga, A.; Bigna, J.J.; Melong, A.; Ntoude, A.; Kamgang, B.; Bouyne, R.; Moundipa Fewou, P.; Demanou, M. Investigation of an Outbreak of Dengue Virus Serotype 1 in a Rural Area of Kribi, South Cameroon: A Cross-Sectional Study. Intervirology 2018, 61, 265-271. [CrossRef] [PubMed]

37. Yousseu, S.F.B.; Nemg, S.F.B.; Ngouanet, A.S.; Mekanda, O.F.M.; Demanou, M. Detection and serotyping of dengue viruses in febrile patients consulting at the new-bell district hospital in Douala, Cameroon. PLoS ONE 2018, 13, e0204143. [CrossRef]

38. Tchuandom, S.B.; Tchouangueu, T.F.; Antonio-Nkondjio, C.; Lissom, A.; Ngono Djang, J.O.; Atabonkeng, E.P.; Kechia, A.; Nchinda, G.; Kuiate, J.-R. Seroprevalence of dengue virus among children presenting with febrile illness in some public health facilities in Cameroon. Pan Afr. Med. J. 2018, 31, 31-38. [CrossRef]

39. Monamele, G.C.; Demanou, M. First documented evidence of dengue and malaria co-infection in children attending two health centers in Yaounde, Cameroon. Pan Afr. Med. J. 2018, 29, 227. [CrossRef]

40. Kamgang, B.; Vazeille, M.; Yougang, A.P.; Tedjou, A.N.; Wilson-Bahun, T.A.; Mousson, L.; Wondji, C.S.; Failloux, A.B. Potential of Aedes albopictus and Aedes aegypti (Diptera: Culicidae) to transmit yellow fever virus in urban areas in Central Africa. Emerg. Microbes Infect. 2019, 8, 1636-1641. [CrossRef]

41. Kamgang, B.; Vazeille, M.; Tedjou, A.N.; Wilson-Bahun, T.A.; Yougang, A.P.; Mousson, L.; Wondji, C.S.; Failloux, A.B. Risk of dengue in Central Africa: Vector competence studies with Aedes aegypti and Aedes albopictus (Diptera: Culicidae) populations and dengue 2 virus. PLoS Negl. Trop. Dis. 2020, 13, e0007985. [CrossRef]

42. Kamgang, B.; Vazeille, M.; Tedjou, A.; Yougang, A.P.; Wilson-Bahun, T.A.; Mousson, L.; Wondji, C.S.; Failloux, A.-B. Different populations of Aedes aegypti and Aedes albopictus (Diptera: Culicidae) from Central Africa are susceptible to Zika virus infection. PLoS Negl. Trop. Dis. 2020, 14, e0008163. [CrossRef] [PubMed] 
43. PAHO. Dengue and Dengue Hemorrhagic Fever in the Americas: Guidelines for Prevention and Control; Pan American Health Organisation: Washington, DC, USA, 1994.

44. WHO. Technical Guide for a System of Yellow Fever Surveillance; World Health Organisation: Geneva, Switzerland, 1971.

45. Camara, D.C.; Codeco, C.T.; Juliano, S.A.; Lounibos, L.P.; Riback, T.I.; Pereira, G.R.; Honorio, N.A. Seasonal Differences in Density But Similar Competitive Impact of Aedes albopictus (Skuse) on Aedes aegypti (L.) in Rio de Janeiro, Brazil. PLoS ONE 2016, 11, e0157120. [CrossRef] [PubMed]

46. Juliano, S.A.; O'Meara, G.F.; Morrill, J.R.; Cutwa, M.M. Desiccation and thermal tolerance of eggs and the coexistence of competing mosquitoes. Oecologia 2002, 130, 458-469. [CrossRef] [PubMed]

47. Tripet, F.; Lounibos, L.P.; Robbins, D.; Moran, J.; Nishimura, N.; Blosser, E.M. Competitive reduction by satyrization? Evidence for interspecific mating in nature and asymmetric reproductive competition between invasive mosquito vectors. Am. J. Trop. Med. Hyg. 2011, 85, 265-270. [CrossRef] [PubMed]

48. Bargielowski, I.E.; Lounibos, L.P.; Carrasquilla, M.C. Evolution of resistance to satyrization through reproductive character displacement in populations of invasive dengue vectors. Proc. Natl. Acad. Sci. USA 2013, 110, 2888-2892. [CrossRef]

49. Bargielowski, I.E.; Lounibos, L.P. Satyrization and satyrization-resistance in competitive displacements of invasive mosquito species. Insect Sci. 2016, 23, 162-174. [CrossRef]

50. Reiskind, M.H.; Lounibos, L.P. Spatial and temporal patterns of abundance of Aedes aegypti L. (Stegomyia aegypti) and Aedes albopictus (Skuse) [Stegomyia albopictus (Skuse)] in southern Florida. Med. Vet. Entomol. 2013, 27, 421-429. [CrossRef]

51. Lounibos, L.P. Invasions by insect vectors of Human disease. Annu. Rev. Entomol. 2002, 47, $233-266$. [CrossRef]

52. Hammond, S.N.; Gordon, A.L.; Lugo, E.D.C.; Moreno, G.; Kuan, G.M.; López, M.M.; López, J.D.; Delgado, M.A.; Valle, S.I.; Espinoza, P.M. Characterization of Aedes aegypti (Diptera: Culcidae) production sites in urban Nicaragua. J. Med. Entomol. 2007, 44, 851-860. [CrossRef]

53. Dutta, P.; Khan, S.A.; Khan, A.M.; Sharma, C.K.; Doloi, P.K.; Mahanta, J. Solid waste pollution and breeding potential of dengue vectors in urban and industrial environmentof Assam. J. Environ. Biol. 1999, 20, $343-345$.

54. Duccombe, J.; Espino, F.; Marollano, K.; Velazco, A.; Ritchie, S.A.; Wenbiao, H.; Weinstein, P.; Clements, A.C.A. Characterising the spatial dynamics of sympatric Aedes aegypti and Aedes albopictus populations in the Philippines. Geospat. Health 2013, 8, 255-265. [CrossRef] [PubMed]

55. Barrera, R.; Amador, M.; Clark, G.G. Ecological factors influencing Aedes aegypti (Diptera: Culicidae) productivity in artificial containers in Salinas, Puerto Rico. J. Med. Entomol. 2006, 43, 484-492. [CrossRef] [PubMed]

56. Cox, J.; Grillet, M.E.; Ramos, O.M.; Amador, M.; Barrera, R. Habitat segregation of dengue vectors along an urban environmental gradient. Am. J. Trop. Med. Hyg. 2007, 76, 820-826. [CrossRef] [PubMed]

57. Alto, B.W.; Lounibos, L.P.; Mores, C.N.; Reiskind, M.H. Larval competition alters susceptibility of adult Aedes mosquitoes to dengue infection. Proc. Biol. Sci. 2008, 275, 463-471. [CrossRef] [PubMed]

58. Lutomiah, J.; Barrera, R.; Makio, A.; Mutisya, J.; Koka, H.; Owaka, S.; Koskei, E.; Nyunja, A.; Eyase, F.; Coldren, R.; et al. Dengue outbreak in Mombasa city, Kenya, 2013-2014: Entomologic investigations. PLoS Negl. Trop. Dis. 2016, 10, e0004981. [CrossRef] [PubMed]

59. Getachew, D.; Tekie, H.; Gebre-Michael, T.; Balkew, M.; Mesfin, A. Breeding Sites of Aedes aegypti: Potential Dengue Vectors in Dire Dawa, East Ethiopia. Interdiscip. Perspect. Infect. Dis. 2015, 2015, 706276. [CrossRef]

60. Mboera, L.E.; Mweya, C.N.; Rumisha, S.F.; Tungu, P.K.; Stanley, G.; Makange, M.R.; Misinzo, G.; De Nardo, P.; Vairo, F; Oriyo, N.M. The risk of dengue virus transmission in Dar es Salaam, Tanzania during an epidemic period of 2014. PLoS Negl. Trop. Dis. 2016, 10, e0004313. [CrossRef]

61. BUCREP. Projections Démographiques, 2010th ed.; BUCREP: Yaoundé, Cameroun, 2010; Volume 3, p. 91.

62. Letouzey, R. Notice de la Carte Phytogéographique du Cameroun au 1:500 000 (1985); Institut de la Carte Internationale de la Végétation: Toulouse, France, 1985; p. 50.

63. Anguh Nkwemoh, C.; Tchindjang, M.; Ngwatung Afungang, R. The impact of urbanization on the vegetation of Yaoundé, (Cameroon). Int. J. Innov. Res. Dev. 2017, 6, 6-18. [CrossRef]

64. Jupp, P.G. Mosquitoes of Southern Africa. Culicinae and Toxorhynchitinae; Ekogilde: Hartebeespoort, South Africa, 1996; p. 164.

65. Edwards, J. Mosquitoes of the Ethiopian Region; Oxford University Press: Oxford, UK, 1941; p. 513. 
66. R Core Team. R: A Language and Environment for Statistical Computing; R Foundation for Statistical Computing: Vienna, Austria, 2018.

67. QGIS Development Team. QGIS 3.8.1 Geographic Information System. Open Source Geospatial Foundation Project. 2019. Available online: https://www.npackd.org/p/qgis/3.8.1 (accessed on 2 May 2012). 